$\frac{\text { ARTIGO }}{\text { dOI https://doi.org/10.22481/praxisedu.v16i41.6638 }}$

\title{
ATIVIDADES EXTRACURRICULARES E POLÍTICAS DE AMPLIAÇÃO DA JORNADA ESCOLAR: COMPARAÇÃO ENTRE BRASIL E ESPANHA ${ }^{1}$
}

\author{
EXTRACURRICULAR ACTIVITIES AND EXTENDED SCHOOL DAY POLICIES: \\ COMPARISON BETWEEN BRAZIL AND SPAIN
}

\begin{abstract}
ACTIVIDADES EXTRAESCOLARES Y POLÍTICAS DE AMPLIACIÓN DE LA JORNADA ESCOLAR: COMPARACIÓN ENTRE BRASIL Y ESPAÑA
\end{abstract}

\author{
Cláudia da Mota Darós Parente \\ Unesp - Universidade Estadual Paulista - Brasil
}

\begin{abstract}
Resumo: O presente artigo tem como objetivo comparar a oferta de atividades extracurriculares no Brasil e na Espanha, no contexto de formulação e implementação de políticas de ampliação da jornada escolar. A análise focalizou as atividades extracurriculares que compõem as políticas de educação em tempo integral (Brasil) e as atividades extracurriculares após a jornada escolar (Espanha). A comparação entre os dois países foi feita com base nas legislações nacionais e num modelo de análise contendo 12 aspectos da formulação e da implementação de políticas. As normatizações nacionais indicam que as atividades extracurriculares contribuem para a formação integral e estabelecem elevada autonomia às unidades federativas (Brasil) e às escolas (Espanha). No caso brasileiro, as atividades extracurriculares no âmbito da educação em tempo integral são gratuitas, estão sob a responsabilidade dos profissionais da educação e ocorrem de forma integrada ao currículo escolar obrigatório. No caso espanhol, as atividades extracurriculares são custeadas pelas famílias, estão sob a responsabilidade de diferentes profissionais e ocorrem após a jornada escolar compulsória. A comparação entre Brasil e Espanha mostra que as estratégias político-pedagógicas de ampliação da jornada escolar estão diretamente associadas à função social da escola em cada país e à forma como articulam alguns elementos, entre os quais: educação formal e não formal, escolar e não escolar, curricular e extracurricular, compulsório e facultativo.
\end{abstract}

Palavras chave: Ampliação da jornada escolar; Atividades extracurriculares; Educação em tempo integral.

Abstract: This article aims to compare the offer of extracurricular activities in Brazil and Spain, in the context of formulating and implementing of extended school day policies. The analysis has focused on extracurricular activities that make up the full-time education policies (Brazil) and extracurricular

\footnotetext{
1 Apresenta resultados da Pesquisa "Modelos e Experiências de Jornada Escolar na União Europeia: contribuições para a análise das políticas de educação integral em tempo integral no Brasil”, financiada pela Fundação de Amparo à Pesquisa do Estado de São Paulo (FAPESP) - Bolsa de Pesquisa no Exterior (BPE). Pósdoutorado realizado na Universidad de Salamanca.
} 
activities after school hours (Spain). The comparison between the two countries was based on national legislation and an analysis model containing 12 aspects of policy formulation and implementation. National regulations indicate that extracurricular activities contribute to integral formation and establish high autonomy for federative units (Brazil) and schools (Spain). In the Brazilian case, extracurricular activities within the scope of full-time education are free, are under the responsibility of education professionals and are integrated with the compulsory school curriculum. In the Spanish case, extracurricular activities are paid by families, are under the responsibility of different professionals and occur after the compulsory school day. The comparison between Brazil and Spain shows that the strategies that make up the extended school day policies are directly associated with the social function of the school in each country and with the way in which they relation to some elements, among which: formal and non-formal education, school and non-school space, curricular and extracurricular, compulsory and optional.

Keywords: Extended school day; Extracurricular activities; Full-time education.

Resumen: Este artículo tiene como objetivo comparar la oferta de actividades extraescolares en Brasil y España, en el contexto de la formulación e implementación de políticas de ampliación de la jornada escolar. El análisis se centró en actividades extraescolares vinculadas a políticas de educación a tiempo completo (Brasil) y actividades extraescolares después del horario lectivo (España). La comparación entre los dos países se basó en la legislación nacional y en un modelo de análisis compuesto por 12 aspectos de formulación e implementación de políticas. Las regulaciones nacionales indican que las actividades extraescolares contribuyen a la educación integral y establecen una elevada autonomía para las unidades federativas (Brasil) y las escuelas (España). En el caso brasileño, las actividades extraescolares dentro del ámbito de la educación a tiempo completo son gratuitas, están bajo la responsabilidad de los profesionales de la educación y se realizan de manera integrada al currículo escolar compulsorio. En el caso español, las actividades extraescolares son costeadas por las familias, están bajo la responsabilidad de diferentes profesionales y ocurren después del horario lectivo. La comparación entre Brasil y España muestra que las estrategias político-pedagógicas para expandir la jornada escolar están directamente asociadas con la función social de la escuela en cada país y con la forma como relacionan algunos elementos, entre los cuales: educación formal y no formal, escolar y no escolar, curricular y extracurricular, obligatoria y opcional.

Palabras clave: Ampliación de la jornada escolar; Actividades extraescolares; Educación a tiempo completo.

\section{Introdução}

As discussões sobre a temática da jornada escolar não são recentes. Na atualidade, muitos países, a exemplo de Brasil e Espanha, vêm investindo em políticas de ampliação da jornada escolar (extended school day policies), o que propicia uma nova abordagem em relação ao tema.

As políticas de ampliação da jornada escolar têm como pressuposto o aumento do tempo do aluno na escola e estão ancoradas numa série de argumentos, o que poderá resultar em diferentes estratégias político-educacionais. Quanto aos argumentos, mais tempo do aluno 
na escola significa, entre outros, a defesa de mais oportunidades educativas, mais tempo em segurança, diminuição da vulnerabilidade social e até mesmo melhores índices educacionais. Quanto às estratégias político-pedagógicas, há um rol muito amplo de possibilidades. De forma geral, as atividades que ampliam o tempo do aluno na escola são chamadas extended school day activities e podem configurar-se em atividades extracurriculares, tempo de cuidado supervisionado e/ou tempo destinado à alimentação escolar. Em alguns países, a junção de várias dessas ações culminará na oferta da educação em tempo integral (full-time education/all-day school/educación a tiempo completo/scuola a tempo pieno).

Em virtude da diversidade de argumentos e de estratégias político-pedagógicas contidas nas políticas de ampliação da jornada escolar de cada país, as investigações da área também possuem nuances próprias. No Brasil, tendo em vista a prevalência de uma jornada escolar reduzida em consonância com o advento dos turnos escolares desde o início do século XX, sobressaíram-se pesquisas com foco na ampliação da jornada escolar por meio da educação em tempo integral (PARO et al., 1988; MIGNOT, 1989; FERRETTI; VIANNA; SOUZA, 1991; CAVALIERE; COELHO, 2002; RIBETTO; MAURÍCIO, 2009; PARENTE, 2018). Na Espanha, diferentes autores contribuíram para a temática da jornada escolar (PEREYRA, 2002, 2005; FERNANDEZ ENGUITA, 2001; LÁZARO HERRERO, 2007, 2017) e entre as discussões mais relevantes estão os embates entre o que os pesquisadores denominaram jornada partida e jornada contínua.

Atualmente, no Brasil, existem dois tipos de jornada escolar: jornada parcial com o mínimo de 4 horas e jornada integral com o mínimo de 7 horas. Durante o século XX, as escolas brasileiras conviveram, majoritariamente, com a jornada parcial. Principalmente nas últimas duas décadas, vem crescendo a oferta de educação em tempo integral. Ainda que não seja a regra, tem-se como ideal a oferta de educação integral em tempo integral, ou seja, mais tempo de escola (tempo integral) para proporcionar uma formação integral (educação integral).

$\mathrm{Na}$ Espanha, atualmente existem dois tipos de jornada escolar: jornada partida, com aulas na parte da manhã e da tarde, com pausa de 2 horas para o almoço; e jornada contínua, com aulas concentradas apenas na parte da manhã e sem pausa para o almoço. A jornada escolar, partida ou contínua, tem uma carga horária de 5 horas, incluídos 30 minutos de recreio. Até a década de 1980, em todo o país, as escolas funcionavam com jornada partida. A partir desse momento, a jornada partida passou a ser questionada por diferentes grupos e por diversas razões, iniciando um movimento para a implementação da jornada contínua. 
No caso brasileiro, a educação em tempo integral possibilita a oferta de atividades que extrapolam as horas e os aspectos curriculares mínimos definidos pela legislação educacional, incluindo a oferta de atividades extracurriculares, comumente denominadas atividades complementares, ou seja, atividades que complementam o currículo escolar. Quando ocorre a oferta de educação em tempo integral, o tempo que o aluno permanece na escola, em atividades curriculares ou extracurriculares, passa a ser compulsório. No caso espanhol, independentemente do tipo de jornada escolar (partida ou contínua), as escolas têm ampla autonomia para oferecer atividades extracurriculares (actividades extraescolares), sempre com a aprovação dos respectivos conselhos escolares e, em geral, gestionadas pelas associações de mães e pais de alunos. São atividades facultativas aos alunos e devem ser custeadas pelas famílias.

Expostos esses apontamentos gerais, o presente artigo tem como objetivo comparar a oferta de atividades extracurriculares no Brasil e na Espanha, no contexto de formulação e implementação de políticas de ampliação da jornada escolar.

\section{Atividades Extracurriculares: aspectos teórico-conceituais}

A oferta de atividades extracurriculares é uma das estratégias político-pedagógicas utilizadas pelas políticas de ampliação da jornada escolar. Assim, primeiramente, é imprescindível delimitar o significado de atividades extracurriculares. Do ponto de vista legal, as atividades curriculares são aquelas definidas oficialmente pela legislação de cada país. Geralmente, as atividades curriculares são expressas por meio de componentes curriculares obrigatórios e estão estreitamente associadas à jornada escolar compulsória (compulsory education). No entanto, existem muitas nuances entre os países: é possível que na jornada escolar compulsória existam outros tempos compulsórios, a exemplo da oferta de alimentação escolar, de tempos supervisionados e até mesmo de atividades extracurriculares. Essas especificidades devem ser compreendidas não apenas sob o prisma das singularidades de cada país, mas também do ponto de vista das mudanças na função sócio-histórica da educação e da escola.

Assim, de forma geral, as atividades extracurriculares podem ser entendidas como um tipo de atividade que vai além do currículo escolar e que contribui para a formação das crianças, adolescentes e jovens em idade de escolarização obrigatória. Em grande medida, estão associadas à área de esportes, artes, línguas e tecnologias. Comumente, as atividades 
extracurriculares são de frequência facultativa, ou seja, são de livre escolha do aluno e de suas famílias. No entanto, mais uma vez é importante destacar que qualquer alteração na função social da escola e no seu currículo repercutirá na delimitação entre: o que é curricular e o que é extracurricular; o que é obrigatório e o que é facultativo.

Ademais, a referência ao termo extracurricular, amiúde, extrapola a simples contraposição ao currículo, à escola e à educação formal, adentrando no terreno da denominada educação não formal. Isso justifica o uso do termo extraescolar ora como sinônimo de extracurricular, ora como definição de atividades extracurriculares que ocorrem em espaços não escolares.

Neste artigo, para fins de exposição e análise, será utilizado genericamente o termo atividades extracurriculares para fazer menção às estratégias político-pedagógicas que os dois países definiram para ampliar o tempo do aluno na escola, seja por meio da educação em tempo integral (Brasil) ou da oferta das actividades extraescolares (Espanha). Durante o exercício comparativo, serão mencionadas as singularidades de cada país e reiteradas as especificidades terminológicas, quando necessário.

Autores que discutem a função e a organização da escola são enfáticos em relação aos processos históricos, sociais e culturais que influenciam na sua constituição (PETITAT, 1994; CANÁRIO, 2005; LIMA, 2011). Na atualidade, o Movimento de Educação para Todos (UNESCO, 2015) exemplifica a relevância da escolarização obrigatória a crianças, adolescentes e jovens e reforça a importância da escola como instituição social promotora da socialização do conhecimento e do acesso ao direito à educação. No entanto, educação e escola nunca foram sinônimos, o que resulta na ideia de que, por um lado, a educação escolar é apenas uma parte da educação e, por outro, a escola não é capaz de atender todas as necessidades formativas de seus sujeitos. Compreendendo a educação como um processo que ocorre durante toda a vida e que envolve diferentes aspectos da formação humana (afetivos, cognitivos, culturais, estéticos, éticos, filosóficos, físicos, religiosos, políticos, psicológicos, sociais etc.), ao longo de sua história, exigiu-se da instituição escolar uma parcela de responsabilidade sobre tais aspectos. Essas definições não são estáticas e variam em cada sociedade e em cada momento histórico, ou seja, a função da escola sempre advém de uma seleção sócio-histórica e cultural.

Esses apontamentos mostram a complexidade do fenômeno educativo e sustentam o conceito de educação integral que se fortaleceu no contexto brasileiro ao longo do século XX. Muitos autores utilizam esse conceito para defender a ampliação da função social da escola, 
com repercussões no currículo e nas escolhas didático-metodológicas dos profissionais da educação. No entanto, o conceito de educação integral (formação integral) associou-se também à ampliação do tempo do aluno na escola (tempo integral), como uma possibilidade a mais de promover melhores oportunidades formativas aos sujeitos da educação, muitos dos quais imersos em precárias condições socioeconômicas. A educação integral em tempo integral tem sido objeto de estudos de vários pesquisadores a exemplo de Moll et. al. (2012).

Na Espanha, essa concepção ampliada do fenômeno educativo foi bastante difundida a partir da década de 1990, em meio ao fortalecimento da ideia de cidade educadora (LA CIUDAD EDUCADORA, 1990; GARCIA GARRIDO, 2000). A ideia de cidade educadora articula os diferentes processos educativos (formais, não formais e informais) e os diversos espaços da ação educativa, com ênfase no planejamento e na integração de ações que ocorrem (ou podem ocorrer) na cidade. Há estreita articulação entre o conceito de educação integral e a ideia de cidade educadora, já que "el concepto de ciudad educadora pretende abarcar todas las dimensiones de la idea de educación integral", ou seja, deve culminar numa "formación que abarque armoniosamente todas las dimensiones de la personalidad humana", ou seja, “[...] intelectual, física, estética y moral, formación para el trabajo y para el ocio, adquisición de conocimientos, de destrezas, de hábitos, de actitudes y de valores" (TRILLA, 1990, p. 18).

Conforme mencionado, as mudanças nas concepções de educação produzem alterações na função social da escola e, por isso, ao longo de sua trajetória histórica, a escola passou por transformações que alteraram sua dinâmica, a organização de seus tempos e seu currículo (MOREIRA; SILVA, 2008; ARROYO, 2011; SACRISTÁN, 2013).

Em meio aos dilemas e desafios da formação integral e diante dos limites e contornos da educação escolar e de seu currículo, há tempos investigadores defendem a relevância da oferta de atividades extracurriculares. Fernández Enguita (2001), em seu estudo sobre a jornada escolar, apresenta um conjunto de razões para se investir nas atividades extracurriculares, pois contribuem para a formação integral dos estudantes por meio de ações não completamente atendidas pela escola, estimulando as inclinações e preferências dos estudantes.

Trilla (1998), ao caracterizar e classificar a educação não formal, explica que há muitas proximidades com a educação formal e até confusão entre seus âmbitos de atuação, o que explica os limites de se estabelecer contornos estáticos entre escolar e não escolar e, consequentemente, entre curricular e extracurricular. Segundo o autor, a educação não formal pode cumprir um papel de substituição, de suplência, de reforço e de compensação em relação à educação formal. No entanto, os objetivos e âmbitos da educação não formal vão mais além 
do que complementar a função da escola. Para o autor, a educação não formal, entre outras possibilidades, ocorre no tempo livre da infância, da adolescência e da juventude. Portanto, em se tratando da educação de sujeitos em fase de escolarização obrigatória, ou seja, de crianças, adolescentes e jovens que frequentam a escola formal num determinado tempo do dia, há lógica em denominar as demais atividades que realizam de atividades extracurriculares, isto é, para além do que a escola formal oferece.

Os elementos expostos explicam porque o que é extracurricular num país ou momento histórico pode ser curricular em outro. A exposição também esclarece porque determinadas atividades extracurriculares podem ser oferecidas no âmbito da educação formal ou da educação não formal, em espaços escolares e não escolares, como atividades compulsórias ou atividades facultativas. Em consequência, isso também explica a diversidade de estratégias político-pedagógicas que ampliam o tempo do aluno na escola, alterando ou não a jornada escolar compulsória, tornando ou não as atividades extracurriculares compulsórias. Essas explanações são essenciais para situar as estratégias político-pedagógicas de Brasil e Espanha.

\section{Delineamento da Pesquisa}

Entre as finalidades da educação comparada está a sistematização de diferenças e semelhanças de diversos sistemas educativos para compreender melhor o próprio país. Há, portanto, o pressuposto de que uma análise comparada de dois ou mais países, sem objetivos de transposições e devidamente contextualizada, traz grandes benefícios à compreensão dos sistemas educativos e de suas especificidades (GARCIA GARRIDO, 1982; FERRER JULIÁ, 2002). Diante das muitas unidades de comparação (BRAY; ADAMSON; MASON, 2015), o presente estudo concentra-se num elemento específico dos sistemas educativos dos dois países: as atividades extracurriculares.

$\mathrm{Na}$ área da educação, a comparação entre Brasil e Espanha, embora não seja recorrente, foi alvo de investigações recentes com diferentes finalidades (SOUZA; BATISTA, 2017, 2018; CRUZ; CASTIONI, 2018, 2019; PARENTE, LÁZARO HERRERO, 2019). No que se refere à jornada escolar, há muito ainda a ser explorado. Assim, tem-se como problemática de investigação: como Brasil e Espanha organizam a oferta de atividades extracurriculares e como elas se relacionam à jornada escolar e à sua ampliação?

A comparação entre Brasil e Espanha será feita com base na legislação nacional dos dois países, com foco nas normativas direcionadas aos anos iniciais do ensino fundamental, 
no caso brasileiro, e à educación primaria, no caso espanhol. O exercício comparativo terá como referência um Modelo de Análise de Políticas de Ampliação da Jornada Escolar composto por 12 critérios (Quadro 1), adaptado da tipologia de políticas de educação em tempo integral (PARENTE, 2016). Primeiramente, serão apresentados os principais elementos que caracterizam a oferta de atividades extracurriculares nos dois países. Em seguida, com base no modelo de análise citado, serão comparados os aspectos de formulação e implementação da política no Brasil e na Espanha, evidenciando diferenças e semelhanças na oferta de atividades extracurriculares.

Quadro 1: Modelo de Análise das Políticas de Ampliação da Jornada Escolar

\begin{tabular}{|c|c|c|}
\hline Aspecto & Critério & Classificação \\
\hline \multirow{8}{*}{ Formulação da Política } & \multirow[t]{2}{*}{ Normatização da política } & Estruturada \\
\hline & & Semiestruturada \\
\hline & \multirow{2}{*}{$\begin{array}{lr}\text { Formulação } & \mathrm{e} \\
\text { implementação } & \mathrm{da} \\
\text { política } & \end{array}$} & $\begin{array}{l}\text { Formulada e implementada no mesmo nível administra- } \\
\text { tivo/governamental }\end{array}$ \\
\hline & & $\begin{array}{l}\text { Formulada e implementada por diferentes níveis } \\
\text { administrativos/governamentais }\end{array}$ \\
\hline & \multirow[t]{2}{*}{ Abrangência da política } & Universal \\
\hline & & Parcial \\
\hline & \multirow[t]{2}{*}{ Argumento da política } & Sustentada por argumentos educativos \\
\hline & & Sustentada por argumentos sociais \\
\hline \multirow{16}{*}{$\begin{array}{l}\text { Implementação da } \\
\text { Política }\end{array}$} & \multirow{2}{*}{$\begin{array}{l}\text { Existência de relações } \\
\text { intersetoriais }\end{array}$} & Implementada apenas pelo setor educacional \\
\hline & & Implementada intersetorialmente \\
\hline & \multirow{2}{*}{$\begin{array}{l}\text { Origem dos recursos da } \\
\text { política }\end{array}$} & Implementada com recursos públicos \\
\hline & & Implementada com recursos públicos e privados \\
\hline & \multirow{2}{*}{$\begin{array}{l}\text { Existência de relações } \\
\text { público-privadas }\end{array}$} & Implementada pelo Poder Público \\
\hline & & Implementada por meio de relações público-privadas \\
\hline & \multirow{2}{*}{$\begin{array}{lll}\text { Espaço da } & \text { ação } \\
\text { educativa } & & \end{array}$} & Implementada apenas em espaços escolares \\
\hline & & Implementada em espaços escolares e não escolares \\
\hline & \multirow{2}{*}{$\begin{array}{lrr}\begin{array}{l}\text { Formação } \\
\text { sável pela }\end{array} & \text { respon- } \\
\begin{array}{l}\text { educativa } \\
\text { eduo }\end{array} & & \\
\end{array}$} & Implementada por profissionais da educação \\
\hline & & Implementada por diferentes profissionais \\
\hline & \multirow{2}{*}{$\begin{array}{l}\text { Vínculo profissional do } \\
\text { responsável pela ação } \\
\text { educativa }\end{array}$} & Implementada por profissionais concursados \\
\hline & & $\begin{array}{l}\text { Implementada por profissionais com diferentes vínculos } \\
\text { profissionais }\end{array}$ \\
\hline & \multirow{2}{*}{$\begin{array}{ll}\text { Organização } & \text { das } \\
\text { atividades } & \\
\text { extracurriculares } & \end{array}$} & Padronizada \\
\hline & & Não padronizada \\
\hline & \multirow{2}{*}{$\begin{array}{lc}\text { Articulação } & \text { das } \\
\text { atividades } & \\
\text { extracurriculares } & \text { ao } \\
\text { currículo obrigatório } & \end{array}$} & Integradas \\
\hline & & Não integradas \\
\hline
\end{tabular}

Fonte: Elaborado pela autora, adaptado de Parente (2016). 


\section{Oferta de Atividades Extracurriculares: especificidades de Brasil e Espanha}

Brasil é uma República Federativa presidencialista organizada em 26 estados e um Distrito Federal. Cada estado possui seus respectivos municípios e todos têm autonomia para criar seus respectivos sistemas de ensino. Em vista da descentralização da organização da educação brasileira, estados e municípios podem estabelecer suas próprias diretrizes no que se refere à jornada escolar, contanto que respeitem a definição nacional: jornada parcial com o mínimo de 4 horas e jornada integral com o mínimo de 7 horas (BRASIL, 1996²).

Ainda que seja tarefa difícil generalizar a jornada escolar do país, já que há muitas possibilidades organizativas, o Quadro 2 apresenta uma configuração básica dos dois tipos de jornada escolar, com base na carga horária mínima definida legalmente. Adicionalmente, o quadro exemplifica uma forma (entre muitas outras) de como as atividades extracurriculares são oferecidas em escolas com jornada integral.

Quadro 2 - Jornada Escolar (Parcial e Integral) e Oferta de Atividades Extracurriculares Brasil

\begin{tabular}{|c|c|c|c|c|c|c|c|}
\hline \multicolumn{2}{|c|}{$\begin{array}{c}\text { JORNADA } \\
\text { PARCIAL MANHÃ }\end{array}$} & \multicolumn{2}{|c|}{$\begin{array}{c}\text { JORNADA } \\
\text { PARCIAL TARDE }\end{array}$} & \multicolumn{4}{|c|}{ JORNADA INTEGRAL } \\
\hline $\begin{array}{l}7 \mathrm{~h} 30- \\
8 \mathrm{~h} 25\end{array}$ & $1^{\text {a }}$ Sessão & $\begin{array}{l}13 \mathrm{~h}- \\
13 \mathrm{~h} 55\end{array}$ & $1^{\mathrm{a}}$ Sessão & $\begin{array}{l}7 \mathrm{~h} 30- \\
8 \mathrm{~h} 25\end{array}$ & $1^{\text {a }}$ Sessão & $\begin{array}{l}11 \mathrm{~h} 30- \\
12 \mathrm{~h} 25\end{array}$ & ALMOÇO \\
\hline $\begin{array}{l}8 \mathrm{~h} 25- \\
9 \mathrm{~h} 20\end{array}$ & $2^{\mathrm{a}}$ Sessão & $\begin{array}{l}13 \mathrm{~h} 55- \\
14 \mathrm{~h} 50\end{array}$ & $2^{\mathrm{a}}$ Sessão & $\begin{array}{l}8 \mathrm{~h} 25- \\
9 \mathrm{~h} 20\end{array}$ & $2^{\mathrm{a}}$ Sessão & $\begin{array}{l}12 \mathrm{~h} 25- \\
13 \mathrm{~h} 20\end{array}$ & $\begin{array}{c}\text { ATIVIDADES } \\
\text { EXTRACURRICULARES }\end{array}$ \\
\hline $\begin{array}{l}9 \mathrm{~h} 20- \\
9 \mathrm{~h} 40\end{array}$ & RECREIO & $\begin{array}{l}14 \mathrm{~h} 50- \\
15 \mathrm{~h} 10\end{array}$ & RECREIO & $\begin{array}{l}9 \mathrm{~h} 20- \\
9 \mathrm{~h} 40\end{array}$ & RECREIO & $\begin{array}{l}13 \mathrm{~h} 20- \\
14 \mathrm{~h} 15\end{array}$ & $\begin{array}{c}\text { ATIVIDADES } \\
\text { EXTRACURRICULARES }\end{array}$ \\
\hline $\begin{array}{l}9 \mathrm{~h} 40- \\
10 \mathrm{~h} 35\end{array}$ & $3^{\text {a }}$ Sessão & $\begin{array}{l}15 \mathrm{~h} 10- \\
16 \mathrm{~h} 05\end{array}$ & $3^{\mathrm{a}}$ Sessão & $\begin{array}{l}9 \mathrm{~h} 40- \\
10 \mathrm{~h} 35\end{array}$ & $3^{\text {a }}$ Sessão & $\begin{array}{l}14 \mathrm{~h} 15- \\
14 \mathrm{~h} 30\end{array}$ & RECREIO \\
\hline $\begin{array}{l}10 \mathrm{~h} 35- \\
11 \mathrm{~h} 30\end{array}$ & $4^{\mathrm{a}}$ Sessão & $\begin{array}{c}16 \mathrm{~h} 05- \\
17 \mathrm{~h}\end{array}$ & $4^{\mathrm{a}}$ Sessão & $\begin{array}{l}10 \mathrm{~h} 35- \\
11 \mathrm{~h} 30\end{array}$ & $4^{\mathrm{a}}$ Sessão & & \\
\hline \multicolumn{2}{|c|}{$\begin{array}{l}4 \text { horas, com } 20 \\
\text { minutos de recreio }\end{array}$} & \multicolumn{2}{|c|}{$\begin{array}{l}4 \text { horas, com } 20 \\
\text { minutos de recreio }\end{array}$} & \multicolumn{4}{|c|}{$\begin{array}{c}7 \text { horas, com } 55 \text { minutos de almoço e dois intervalos (35 } \\
\text { minutos) }\end{array}$} \\
\hline
\end{tabular}

Elaborado pela autora.

Em virtude dos turnos escolares, na maioria das escolas brasileiras, públicas ou privadas, os alunos estudam somente meio período, na parte da manhã ou da tarde. Muitas escolas também oferecem escolarização no período noturno, geralmente, para atendimento a estudantes trabalhadores e para a educação de jovens e adultos que desejam finalizar seus estudos.

Novamente é importante mencionar que a oferta de atividades extracurriculares pode ocorrer fora do sistema educacional, no âmbito da educação não formal. Neste artigo, a

\footnotetext{
${ }^{2}$ E alterações posteriores.
} 
análise focaliza apenas a oferta de atividades extracurriculares no âmbito da educação pública e no contexto de formulação e implementação de políticas de educação em tempo integral. Ademais, conforme destacado, a educação em tempo integral pode envolver uma série de elementos na composição do tempo que o aluno permanece na escola. Neste artigo, o foco está apenas nas atividades extracurriculares. Deve-se destacar que, no contexto da educação em tempo integral, todo o tempo que o aluno permanece na escola passa a ser compulsório, independentemente das atividades que englobem esse período.

Por sua vez, a Espanha é uma Monarquia com governo parlamentar e está organizada em 17 Comunidades Autônomas e 2 Cidades Autônomas. As Comunidades Autônomas têm autonomia para organizar seus respectivos sistemas educativos, inclusive definir o tipo de jornada escolar: partida, com aulas na parte da manhã e da tarde; ou contínua, com aulas apenas na parte da manhã. Independentemente da jornada escolar, as escolas têm uma carga horária de 5 horas, com 30 minutos de recreio. No caso da jornada partida, há duas horas de pausa para o almoço. Nesse período, o aluno pode ir para sua casa almoçar ou ficar nas dependências da escola e fazer uso (com ou sem subvenção estatal) dos serviços do comedor escolar.

Ainda que haja muitas possibilidades de organização da jornada escolar em termos de horário nas diversas Comunidades Autônomas, o Quadro 3 sistematiza, minimamente, as diferenças entre jornada partida e contínua, além de mostrar que as atividades extracurriculares, geralmente, ocorrem das $16 \mathrm{~h}$ às $18 \mathrm{~h}$.

Quadro 3 - Jornada Escolar (partida e contínua) e Oferta de Atividades Extracurriculares Espanha

\begin{tabular}{|c|c|c|c|}
\hline \multicolumn{2}{|c|}{ JORNADA PARTIDA } & \multicolumn{2}{|c|}{ JORNADA CONTÍNUA } \\
\hline $9 \mathrm{~h}-9 \mathrm{~h} 45$ & $1^{\mathrm{a}}$ sessão & $9 \mathrm{~h}-9 \mathrm{~h} 45$ & $1^{\mathrm{a}}$ sessão \\
\hline 9h45-10h30 & $2^{\mathrm{a}}$ sessão & 9h45-10h30 & $2^{\mathrm{a}}$ sessão \\
\hline 10h30-11h15 & $3^{\mathrm{a}}$ sessão & 10h30-11h15 & $3^{\mathrm{a}}$ sessão \\
\hline 11h15-11h45 & RECREIO & 11h15-11h35 & RECREIO \\
\hline \multirow{2}{*}{$11 \mathrm{~h} 45-12 \mathrm{~h} 30$} & \multirow{2}{*}{$4^{a}$ sessão } & $11 \mathrm{~h} 35-12 \mathrm{~h} 20$ & $4^{\mathrm{a}}$ sessão \\
\hline & & $12 \mathrm{~h} 20-13 \mathrm{~h} 05$ & $5^{\mathrm{a}}$ sessão \\
\hline $12 \mathrm{~h} 30-14 \mathrm{~h} 30$ & ALMOÇO & $13 \mathrm{~h} 05-13 \mathrm{~h} 15$ & RECREIO \\
\hline $14 \mathrm{~h} 30-15 \mathrm{~h} 15$ & $5^{a}$ sessão & $13 \mathrm{~h} 15-14 \mathrm{~h}$ & $6^{\mathrm{a}}$ sessão \\
\hline $15 \mathrm{~h} 15-16 \mathrm{~h}$ & $6^{\mathrm{a}}$ sessão & $14 \mathrm{~h}-16 \mathrm{~h}$ & ALMOÇO \\
\hline $16 \mathrm{~h} 00-18 \mathrm{~h} 00$ & $\begin{array}{c}\text { ATIVIDADES } \\
\text { EXTRACURRICULARES }\end{array}$ & $16 \mathrm{~h} 00-18 \mathrm{~h} 00$ & $\begin{array}{c}\text { ATIVIDADES } \\
\text { EXTRACURRICULARES }\end{array}$ \\
\hline \multicolumn{2}{|c|}{5 horas letivas, com 30 minutos de recreio } & \multicolumn{2}{|c|}{5 horas letivas, 30 minutos de recreio } \\
\hline
\end{tabular}

Elaborado pela autora 


\section{Oferta de Atividades Extracurriculares: aspectos da formulação da política}

Seguindo o modelo de análise proposto no Quadro 1 deste artigo, a análise comparada das legislações nacionais possibilitou a sistematização das principais características da oferta de atividades extracurriculares no Brasil e na Espanha (Quadro 4).

Quadro 4: Oferta de Atividades Extracurriculares - Aspectos da Formulação da Política Brasil e Espanha

\begin{tabular}{|c|c|c|c|}
\hline Aspecto & Critério & Brasil & Espanha \\
\hline \multirow{4}{*}{$\begin{array}{l}\text { Formulação } \\
\text { da Política }\end{array}$} & $\begin{array}{l}\text { Normatização } \\
\text { política }\end{array}$ & $\begin{array}{l}\text { Estruturada em âmbito nacional, } \\
\text { com elevada autonomia das } \\
\text { unidades federativas }\end{array}$ & $\begin{array}{l}\text { Estruturada em âmbito nacional, } \\
\text { com elevada autonomia das } \\
\text { Comunidades Autônomas e dos } \\
\text { conselhos escolares }\end{array}$ \\
\hline & $\begin{array}{lr}\text { Formulação } & \mathrm{e} \\
\text { implementação da } \\
\text { política }\end{array}$ & $\begin{array}{l}\text { Formulada e implementada em } \\
\text { diferentes níveis governamentais, } \\
\text { com elevada autonomia das } \\
\text { unidades federativas }\end{array}$ & $\begin{array}{l}\text { Formulada e implementada em } \\
\text { diferentes níveis governamentais, } \\
\text { com elevada autonomia dos } \\
\text { conselhos escolares }\end{array}$ \\
\hline & $\begin{array}{l}\text { Abrangência } \\
\text { política }\end{array}$ & $\begin{array}{l}\text { Parcial (a definição da oferta } \\
\text { ocorre no âmbito das unidades } \\
\text { federativas) }\end{array}$ & $\begin{array}{l}\text { Parcial (a definição da oferta } \\
\text { ocorre no âmbito dos conselhos } \\
\text { escolares) }\end{array}$ \\
\hline & $\begin{array}{l}\text { Argumento } \\
\text { política }\end{array}$ & $\begin{array}{l}\text { Argumentos educativos e sociais, } \\
\text { com prevalência do segundo }\end{array}$ & $\begin{array}{l}\text { Argumentos educativos e sociais, } \\
\text { com prevalência do primeiro }\end{array}$ \\
\hline
\end{tabular}

Elaborado pela autora.

No Brasil, nas últimas décadas, a ampliação de políticas de educação em tempo integral teve grande respaldo da legislação educacional. Assim, quanto à normatização, o país vem estabelecendo formas de regulação acerca da ampliação da jornada escolar e da oferta de atividades extracurriculares, o que indica a formulação de políticas cada vez mais estruturadas, ou seja, políticas com nível elevado de normatização. Essas regulações vêm ocorrendo tanto por meio de diretrizes nacionais da educação brasileira (BRASIL, 1996, 2007a, 2007b; 2014), como por meio de definições no âmbito dos sistemas de ensino de Estados e Municípios.

No que se refere ao formulador da política, a União, por meio de seus respectivos órgãos, tem a responsabilidade de coordenar a política nacional de educação. No entanto, conforme mencionado, Estados e Municípios têm a liberdade de organizar seus próprios sistemas de ensino (BRASIL, 1996), respeitando a legislação nacional e criando sua própria legislação e política educacional. Em meio a esse cenário, é possível ter políticas formuladas e implementadas no mesmo âmbito administrativo e políticas formuladas e implementadas por 
diferentes níveis governamentais. Ou seja, num único Município é possível encontrar políticas de educação em tempo integral emanadas pela esfera federal, estadual e municipal.

Impulsionados pela legislação citada, os dados estatísticos mostram o crescimento do número de matrículas e de escolas com jornada integral nos anos iniciais do ensino fundamental: 19\% dos estudantes têm uma jornada integral e cerca de 23,8\% das escolas têm esse tipo de oferta (BRASIL, 2018a). Assim, em termos de abrangência da política, a oferta de educação em tempo integral é parcial no território brasileiro. A própria legislação nacional, a exemplo da meta do Plano Nacional de Educação (BRASIL, 2014), indica a parcialidade do atendimento, ou seja, não há pretensão de atendimento em tempo integral a todos.

Em termos de argumentos da política, são visíveis as relações entre argumentos educativos e sociais. A trajetória histórica da educação brasileira e as indicações legais (BRASIL, 2010, 2014) mostram tentativas de conciliação entre os dois tipos de argumento: melhores oportunidades educativas por meio da oferta de educação em tempo integral e, ao mesmo tempo, definição de estratégias sociais para seleção de alunos beneficiários, já que não é uma ação destinada a todos. A educação em tempo integral atua como estratégia de correção de desigualdades externas ao sistema educacional. No entanto, à medida que as atividades extracurriculares são seletivas, podem também produzir desigualdades dentro do próprio sistema educacional.

$\mathrm{Na}$ Espanha, no contexto de discussão das jornadas escolares contínua e partida sempre houve, de alguma forma, espaço para refletir sobre a função das atividades extracurriculares. No entanto, desde os anos de 1990, no contexto de implementação do Programa de Apertura de Centros en Horario no Lectivo, o país passou a defender a oferta de atividades extracurriculares na própria escola e a abertura dos prédios escolares para além do horário letivo (jornada compulsória). Desde esse período, em termos de normatização da política, produziu-se um conjunto estruturado de definições e orientações para a oferta de atividades extracurriculares (ESPANHA, 1994a, 1994b, 1995, 1996a, 1996b).

A partir das indicações gerais, as Comunidades Autônomas e suas respectivas escolas responsabilizam-se pela organização, aprovação e gestão da oferta de atividades extracurriculares. Essas informações indicam que as ações são formuladas e implementadas em diferentes níveis governamentais. Além da liberdade de as Comunidades Autônomas definirem suas próprias normativas, o país concede grande autonomia às escolas no que se refere às decisões sobre a oferta das atividades extracurriculares. Existem normatizações 
nacionais que regulam a autonomia das escolas e de suas relações com o entorno por meio dos conselhos escolares e das associações de mães e pais de alunos (ESPANHA, 1985, 1986, 1995, 2013).

Apesar da disseminação da ideia de abertura dos prédios escolares em horário não letivo, a participação nas atividades extracurriculares sempre teve um caráter voluntário às famílias, ou seja, a participação é facultativa aos alunos. Esse aspecto explica porque, em termos de abrangência da política, a oferta de atividades extracurriculares é parcial nas escolas espanholas. Em função de as atividades curriculares não estarem integradas à educação compulsória, não existem dados oficiais relativos à sua oferta. As estatísticas nacionais apresentam apenas dados de escolas que ampliam seu horário de funcionamento antes e/ou depois do horário letivo. Os dados mostram que apenas 6\% dos alunos das escolas primárias fazem uso desse serviço (ESPANHA, 2019). No entanto, esse dado não se mostra fidedigno no que se refere às atividades extracurriculares.

Quanto aos argumentos da política, ainda na década de 1990, o Ministério da Educação produziu o documento Las Actividades Extraescolares en los Centros Educativos, com a finalidade de promover e potencializar a oferta de atividades extracurriculares nas escolas, a fim de: complementar a oferta educativa com novas atividades; oferecer espaço para o tempo livre dos alunos; aproveitar as instalações das escolas. Com base no documento, tais atividades deveriam promover: educação integral aos alunos; melhora de suas capacidades; utilização saudável de seu tempo livre; ampliação de seus recursos durante o tempo livre (ESPANHA, 1996a).

Tais aspectos evidenciam que a oferta de atividades extracurriculares está estreitamente ancorada em argumentos educativos, com forte associação a elementos sociais. Isso porque, são argumentos associados à ampliação da equidade. Antes da década de 1990, a oferta de atividades extracurriculares estava condicionada às possibilidades econômicas das famílias, o que gerava desigualdade. Assim, a oferta de atividades extracurriculares na própria escola é também uma maneira de promoção da equidade, ainda que outros tipos de desigualdades possam ser criados a depender das atividades, de seus custos e especificidades. Em todo caso, as atividades extracurriculares têm a função de melhorar as oportunidades educativas e, ao mesmo tempo, estreitar a relação escola-comunidade, o que indica a existência de argumentos educativos e sociais, com prevalência dos primeiros. 


\section{Oferta de Atividades Extracurriculares: aspectos da implementação da política}

Analisados os principais aspectos legais que sustentam a oferta de atividades extracurriculares no Brasil e na Espanha, é possível sistematizar alguns aspectos que explicam suas opções em termos de implementação de políticas (Quadro 5).

Quadro 5: Oferta de Atividades Extracurriculares - Aspectos da implementação da política Brasil e Espanha

\begin{tabular}{|c|c|c|c|}
\hline Aspecto & Critério & Brasil & Espanha \\
\hline \multirow{8}{*}{$\begin{array}{l}\text { Implementação } \\
\text { da Política }\end{array}$} & $\begin{array}{l}\text { Existência de relações } \\
\text { intersetoriais }\end{array}$ & $\begin{array}{l}\text { Sim, como estratégia para } \\
\text { otimizar recursos públicos }\end{array}$ & $\begin{array}{l}\text { Sim, como parte da } \\
\text { autonomia da escola }\end{array}$ \\
\hline & $\begin{array}{l}\text { Origem dos recursos da } \\
\text { política }\end{array}$ & $\begin{array}{l}\text { Públicos e privados, com } \\
\text { prevalência dos primeiros }\end{array}$ & $\begin{array}{l}\text { Públicos e privados, como } \\
\text { parte da autonomia da } \\
\text { escola }\end{array}$ \\
\hline & $\begin{array}{l}\text { Existência de relações } \\
\text { público-privadas }\end{array}$ & $\begin{array}{lr}\text { Sim, como estratégia para } \\
\text { incrementar } \\
\text { existentes }\end{array}$ & $\begin{array}{l}\text { Sim, como parte da } \\
\text { autonomia da escola }\end{array}$ \\
\hline & Espaço da ação educativa & $\begin{array}{l}\text { Escolares e não escolares, com } \\
\text { prevalência dos primeiros }\end{array}$ & $\begin{array}{l}\text { Escolares e não escolares, } \\
\text { com prevalência dos } \\
\text { primeiros }\end{array}$ \\
\hline & $\begin{array}{l}\text { Formação do responsável } \\
\text { pela ação educativa }\end{array}$ & $\begin{array}{l}\text { Diferentes profissionais, com } \\
\text { prevalência de profissionais da } \\
\text { educação }\end{array}$ & Diferentes profissionais \\
\hline & $\begin{array}{l}\text { Vínculo profissional do } \\
\text { responsável pela ação } \\
\text { educativa }\end{array}$ & $\begin{array}{l}\text { Profissionais com diferentes } \\
\text { vínculos, com prevalência de } \\
\text { profissionais concursados e } \\
\text { contratados }\end{array}$ & $\begin{array}{l}\text { Profissionais com diferentes } \\
\text { vínculos, com prevalência } \\
\text { de profissionais contratados }\end{array}$ \\
\hline & $\begin{array}{l}\text { Organização das atividades } \\
\text { extracurriculares }\end{array}$ & $\begin{array}{l}\text { Padronizadas no âmbito dos } \\
\text { sistemas de ensino }\end{array}$ & $\begin{array}{l}\text { Não padronizadas, com } \\
\text { definições no âmbito das } \\
\text { escolas }\end{array}$ \\
\hline & $\begin{array}{l}\text { Articulação das atividades } \\
\text { extracurriculares ao } \\
\text { currículo obrigatório }\end{array}$ & $\begin{array}{l}\text { Integradas, geralmente, } \\
\text { sequenciais e no contraturno }\end{array}$ & $\begin{array}{l}\text { Não integradas, geralmente, } \\
\text { ao final da tarde }\end{array}$ \\
\hline
\end{tabular}

Elaborado pela autora.

No Brasil, a legislação educacional oferece margem para diferentes opções em termos de políticas de educação em tempo integral (BRASIL, 2010, 2007b, 2014), criando espaço para a busca de alternativas e possibilidades frente a questões antigas (insuficiência de espaços físicos, por exemplo) e questões novas (relações entre setores, entre Estado e sociedade civil e entre público e privado).

No âmbito do Executivo, o Ministério da Educação e as Secretarias de Educação dos Estados e Municípios brasileiros são atores institucionais importantes na formulação e implementação das políticas educacionais. Apesar disso, ações intersetoriais vêm sendo disseminadas com o objetivo de aproveitar os recursos públicos já existentes nos diferentes 
setores. Quando ocorrem, geralmente, são realizadas por meio de relações entre o setor educativo e outros setores relacionados às políticas sociais (saúde, assistência social, esporte, cultura etc.).

A educação pública brasileira é gratuita mesmo no caso da educação em tempo integral (BRASIL, 1996, 2006, 2007a, 2007b). Ou seja, a matrícula na educação em tempo integral, com suas respectivas atividades extracurriculares, no âmbito das escolas públicas, não gera custos aos alunos e suas famílias. No entanto, muitas políticas de educação em tempo integral vêm utilizando estratégias para o estreitamento entre Estado, mercado e sociedade civil (BRASIL, 2004, 2012, 2014, 2007a, 2007b). A legislação nacional faz apontamentos nessa direção e, portanto, existem ações em curso que, para a implementação da jornada integral, utilizam recursos públicos e privados. Quanto aos recursos privados isso ocorre, por exemplo, por meio de cessões de espaços físicos, materiais e doações, ou seja, uma forma de compensar a ausência de recursos públicos por parte do Estado. Por isso, crescem também ações implementadas por meio de relações público-privadas, com organizações com ou sem fins econômicos. Isso não é uma regra e nem ocorre de forma generalizada, mas as estratégias legais têm conformado as direções das políticas nos últimos anos.

Quanto aos espaços da ação educativa, é possível ter ações implementadas apenas em espaços escolares ou também em espaços não escolares. A legislação nacional brasileira vai em duas direções. Por um lado, estabelece estratégias com o objetivo de melhorar as escolas públicas para que tenham condições materiais de oferecer atividades extracurriculares na própria escola. Por outro lado, definem estratégias para a oferta de atividades extracurriculares por meio de outros espaços, instituições e agentes (BRASIL, 2014). A oferta da educação em tempo integral geralmente ocorre na própria escola, mas é possível encontrar políticas cuja ação educativa ocorre em espaços escolares elou não escolares.

Em termos de responsáveis pela ação educativa, talvez em virtude de as atividades extracurriculares serem compulsórias no âmbito da educação em tempo integral, os profissionais da educação vêm ampliando sua atuação junto aos alunos e, além das atividades curriculares, têm assumido a responsabilidade pelas atividades extracurriculares. No entanto, em função das especificidades das atividades extracurriculares, novos profissionais passaram a integrar a ação educativa, alguns dos quais envolvidos com outros setores e organizações (públicas e privadas). Assim, embora haja prevalência dos profissionais da educação, diferentes profissionais vêm atuando na oferta de atividades extracurriculares. Quanto ao vínculo, é possível ter profissionais com diferentes vínculos. Geralmente são profissionais da 
educação concursados (servidores públicos) e outros profissionais contratados. Assim, existem: políticas que somente utilizam profissionais da educação; políticas que contratam pessoal por prazo determinado para atuação nas atividades extracurriculares; políticas que mesclam diferentes profissionais e com diferentes tipos de contratos de trabalho, inclusive voluntários.

Conforme já mencionado, a jornada integral brasileira é aquela com, pelo menos, 7 horas diárias. Para isso, ao currículo escolar mínimo somam-se atividades complementares, aqui denominadas atividades extracurriculares (BRASIL, 2018b). Quanto ao tipo de atividades, a legislação faz referência a atividades de acompanhamento escolar, culturais, esportivas e recreativas (BRASIL, 2014), o que propicia diferentes atividades extracurriculares. No que se refere à organização curricular, além das orientações nacionais, as unidades federativas podem ter orientações complementares sobre a jornada integral e, a depender de cada política, haverá um nível maior ou menor de autonomia da escola na definição das atividades. No entanto, têm sido recorrentes modelos curriculares de educação em tempo integral padronizados no âmbito das redes de ensino, ou seja, com diretrizes específicas vinculadas a cada política de educação em tempo integral, inclusive, com matriz curricular própria.

Na educação em tempo integral, as atividades extracurriculares somam-se ao currículo escolar mínimo. Do ponto de vista curricular, pode-se dizer que estão integradas ao currículo compulsório do aluno, ou seja, ao tempo que o aluno permanece na escola. Não obstante, em geral, a oferta de atividades extracurriculares ocorre no contraturno, ou seja, após as atividades relacionadas ao currículo escolar mínimo.

Na Espanha, desde a implementação do Programa de Apertura de Centros en Horario no Lectivo, as atividades extracurriculares podem ter um amplo espectro: atividades musicais, teatrais, físicas, esportivas, artísticas, abertura de biblioteca e salas de estudo (ESPANHA, 1996a).

A gestão das atividades extracurriculares ocorre de forma autônoma em cada escola, por meio do conselho escolar, responsável pela aprovação e avaliação do planejamento escolar. Existem atividades de responsabilidade da equipe docente, mas, tradicionalmente, as Asociaciones de Madres y Padres de Alumnos (AMPA) são as responsáveis por organizar a maior parte da oferta de atividades extracurriculares (ESPANHA, 1985, 1986, 1995). Essas associações têm longa trajetória na Espanha. 
Em 1995, a Lei Orgânica n. 9 foi um marco da participação da comunidade educativa no planejamento das atividades extracurriculares. A partir da referida Lei, os governos locais passaram a colaborar com as escolas para impulsionar a oferta de atividades extracurriculares e promover a relação entre a escola e seu entorno. Ainda que as orientações nacionais tenham a pretensão de valorizar a oferta de atividades extracurriculares no âmbito escolar e no âmbito do setor educativo, há também indicações que estimulam relações intersetoriais, ou seja, com setores governamentais relacionados à cultura e ao esporte, por exemplo. Entretanto, são apenas possibilidades que devem orientar as decisões no âmbito de cada escola (ESPANHA, 1996b).

Para a oferta de atividades extracurriculares, os conselhos escolares podem fazer convênios com associações culturais ou organizações sem fins lucrativos (ESPANHA, 1995). Nas orientações do Programa de Apertura de Centros en Horario no Lectivo há indicações sobre o co-financiamento das atividades extracurriculares por parte dos setores implicados: escola, associação de mães e pais de alunos, instituições locais e demais instituições envolvidas (ESPANHA, 1996a).

É importante destacar que as atividades extracurriculares, não sendo parte da educação compulsória, não são de oferta gratuita na sua totalidade, mesmo quando ocorrem nas escolas públicas. Algumas atividades, geralmente aquelas promovidas pela equipe docente, são gratuitas, embora limitadas na forma e nas vagas. Por sua vez, as atividades extracurriculares gestionadas pelas associações de mães e pais envolvem investimentos por parte das famílias. Ademais, é possível articular o aporte financeiro das famílias com recursos captados no âmbito das associações de mães e pais de alunos, assim como recursos já disponíveis no âmbito das escolas e dos governos locais (físicos e humanos, por exemplo). Por conseguinte, para a oferta de atividades extracurriculares são utilizados recursos públicos e privados e, consequentemente, são visíveis as relações público-privadas, sempre com decisões tomadas na esfera das associações de mães e pais e nos conselhos escolares.

Embora o foco da política seja o uso do espaço da escola em horário não letivo, existe a possibilidade de serem estabelecidas colaborações com o governo local (Ayuntamiento) ou outras instituições. Os aspectos citados mostram que as atividades extracurriculares podem ser oferecidas em espaços escolares e não escolares, com prevalência dos primeiros.

A responsabilidade pela oferta de atividades extracurriculares incide sobre diferentes profissionais. A legislação estabelece que os professores devem dedicar cinco horas semanais na escola para, entre outras tarefas, a realização de atividades extracurriculares (ESPANHA, 
1994a). Por sua vez, as associações de mães e pais de alunos contratam profissionais específicos, podendo haver apoio dos governos locais na contratação de recursos humanos.

Conforme o exposto, a organização das atividades extracurriculares é definida no âmbito da própria escola, a cada ano letivo, com ampla autonomia e, portanto, as atividades não são padronizadas. Em termos de integração curricular, embora as atividades extracurriculares colaborem para a formação integral dos alunos, não há integração ao currículo escolar compulsório, ou seja, são ações que ocorrem de forma desvinculada. Apesar disso, são escolhas e decisões feitas no espaço escolar, o que mostra as aproximações entre a formação escolar e as atividades extracurriculares.

\section{Considerações Finais}

O presente artigo teve como objetivo comparar a oferta de atividades extracurriculares no Brasil e na Espanha, no contexto de formulação e implementação de políticas de ampliação da jornada escolar. Para isso, teve como referência um modelo de análise composto por 12 critérios relacionados à formulação e à implementação das políticas nos dois países.

A pesquisa reforça dois elementos que os investigadores em educação comparada reiteradamente mencionam: por um lado, os sistemas educativos estão ancorados em suas respectivas trajetórias históricas; por outro, existem algumas tendências ou elementos relacionados à globalização e à agenda educacional internacional. Ou seja, as políticas de ampliação da jornada escolar estão presentes no cenário internacional, porém, cada país vem criando suas próprias estratégias político-educacionais.

O Brasil chegou ao século XXI com uma jornada escolar reduzida e sem escolas suficientes para a eliminação dos turnos escolares. Atualmente, há coexistência de jornada parcial e integral, com prevalência da primeira. Ainda que em algumas localidades a jornada escolar parcial possa, inclusive, alcançar a jornada escolar espanhola de 5 horas, a permanência dos turnos dificulta o uso do espaço escolar para a oferta de atividades extracurriculares, até mesmo de forma facultativa aos alunos, como ocorre na Espanha. Isso parece ser um dos principais pontos de desvantagem entre as escolas brasileiras e as escolas espanholas, no que se refere ao objeto de estudo deste artigo.

Por sua vez, na Espanha, a análise da jornada escolar mostrou a consolidação da escolarização básica compulsória a todos, com carga horária diária de 5 horas. Atualmente, há coexistência de jornada partida e contínua e, independentemente, do tipo de jornada, o país 
adotou estratégias para oferta de atividades extracurriculares no âmbito das próprias escolas, embora os custos, em sua maior parte, recaiam sobre as famílias.

No Brasil, a oferta de atividades extracurriculares está estreitamente associada às políticas de educação em tempo integral, sem custos aos alunos. No entanto, o atendimento é parcial e, entre outros elementos, está condicionada à existência de recursos públicos e espaços educativos.

Os dois países apresentam grandes expectativas acerca das atividades extracurriculares, já que atuam como importante estratégia para a promoção da educação integral do aluno. No Brasil, as atividades extracurriculares no contexto de educação em tempo integral surgiram, principalmente, como forma de corrigir desigualdades históricas externas à escola, sem, necessariamente, alterar o sistema educativo, mantendo, por exemplo, a dualidade entre escolas públicas e privadas. As atividades extracurriculares dentro do sistema educativo podem também compensar desigualdades existentes entre as próprias escolas públicas, já que algumas políticas costumam investir em localidades mais pobres e vulneráveis social e economicamente. Além disso, há políticas com outros enfoques: algumas utilizam as atividades extracurriculares como forma de melhorar os resultados de avaliações externas, focalizando em atividades compensatórias; há políticas e ações associadas à ampliação do tempo escolar como forma de atender demandas de famílias que trabalham e necessitam que seus filhos fiquem mais tempo na escola, sob a sua supervisão; há políticas que, associadas ou não aos aspectos já citados, se preocupam com uma oferta de qualidade no tempo livre dos estudantes. No caso brasileiro, o importante a destacar é que as atividades extracurriculares/educação em tempo integral ocupam hoje um importante papel no sistema educativo e têm diferentes funções na atualidade, mais ou menos seletivas, compensatórias e/ou associadas a oportunidades de oferecer uma formação integral.

$\mathrm{Na}$ Espanha, as atividades extracurriculares surgiram como forma de garantir equiparação de oportunidades educativas e, portanto, também cumprem uma função social. A abertura das escolas fora do horário letivo, a oferta de atividades extracurriculares mais acessível a todos e, principalmente, a regulação das relações entre escola e comunidade foram algumas das medidas para garantir a disseminação desse tipo de oferta. A relação entre escola-comunidade, a autonomia das escolas espanholas e a gestão das atividades extracurriculares por parte das associações de mães e pais de alunos constituem-se nas principais diferenças em relação às escolas brasileiras. 
O exercício comparativo centrado na oferta de atividades extracurriculares indica a necessidade de reflexões constantes sobre a função social da escola em cada país, com vistas à formulação e implementação políticas de ampliação da jornada escolar que propiciem a melhoria das condições de acesso à formação integral, independentemente dos limites provisórios entre educação formal e não formal, escolar e não escolar e curricular e extracurricular.

\section{REFERÊNCIAS}

ARROYO, Miguel Gonzales. Currículo, território em disputa. Petrópolis: Vozes, 2011.

BRASIL. Lei n. 9.394, 20 de dezembro de 1996. Estabelece as diretrizes e bases da educação nacional. Disponível em: http://www.planalto.gov.br/ccivil_03/leis/19394.htm. Acesso em: 10 abr. 2020.

BRASIL. Lei n. 11.079, de 30 de dezembro de 2004. Institui normas gerais para licitação e contratação de parceria público-privada no âmbito da administração pública. Disponível em: http://www.planalto.gov.br/ccivil_03/_Ato2004-2006/2004/Lei/L11079.htm. Acesso em: 10 abr. 2020.

BRASIL. Emenda constitucional n. 53, de 19 de dezembro de 2006. Disponível em: http://www.planalto.gov.br/ccivil_03/constituicao/Emendas/Emc/emc53.htm Acesso em: 10 abr. 2020.

BRASIL. Lei n. 11.494, de 20 de junho de 2007a. Regulamenta o Fundo de Manutenção e Desenvolvimento da Educação Básica e de Valorização dos Profissionais da Educação FUNDEB [...]. Disponível em: http://www.planalto.gov.br/ccivil_03/_ato20072010/2007/lei/111494.htm. Acesso em: 10 abr. 2020.

BRASIL. Decreto n. 6.253, de 13 de novembro de 2007b. Dispõe sobre o Fundo de Manutenção e Desenvolvimento da Educação Básica e de Valorização dos Profissionais da Educação - FUNDEB [...]. Disponível em: http://www.planalto.gov.br/ccivil_03/_Ato20072010/2007/Decreto/D6253.htm Acesso em: 10 abr. 2020.

BRASIL. Conselho Nacional de Educação. Resolução n. 4, de 13 de julho de 2010. Define Diretrizes Curriculares Nacionais Gerais para a Educação Básica. Disponível em: http://portal.mec.gov.br/dmdocuments/rceb004_10.pdf Acesso em: 10 abr. 2020.

BRASIL. Lei n. 13.005, de 25 de junho de 2014. Aprova o Plano Nacional de Educação [...]. Disponível em: http://www.planalto.gov.br/ccivil_03/_ato2011-2014/2014/lei/113005.htm Acesso em: 10 abr. 2020.

BRASIL. Relatório do $2^{\circ}$ Ciclo de Monitoramento das Metas do Plano Nacional de Educação - 2018. Brasília: INEP, 2018a. Disponível em: http://fne.mec.gov.br/noticias- 
fne/152-relatorio-do-2-ciclo-de-monitoramento-das-metas-do-pne-2018 Acesso em: $10 \mathrm{abr}$. 2020.

BRASIL. Censo Escolar da Educação Básica 2018. Caderno de Instruções. Brasília: MEC/INEP, 2018b. Disponível em:

http://portal.inep.gov.br/documents/186968/484154/Censo+Escolar+da+educação+Básica+20 18+Caderno+de+Instruções/be4e0801-5181-4364-934d-bcaff5ce85ea?version=1.0 Acesso em: 10 abr. 2020.

BRAY, Mark; ADAMSON, Bob; MASON, Mark. Pesquisa em Educação Comparada: abordagens e métodos. Brasília: Liber Livro, 2015.

CANÁRIO, Rui. (org.). O que é escola: um olhar sociológico. Porto: Porto Editora, 2006.

CAVAlIERE, Ana Maria; COELHO, L. M. C. (Orgs.). Educação brasileira em tempo integral. Petrópolis: Vozes, 2002.

CRUZ, Rita de Cássia; CASTIONI, Reni. Desafios en la ampliación del tiempo escolar en dos contextos. Pro-Posições, n. 30, p. 1-17. Disponível em:

https://periodicos.sbu.unicamp.br/ojs/index.php/proposic/article/view/8656545 Acesso em: 10 abr. 2020.

ESPANHA. Ley Orgánica n. 8, de 3 de julio de 1985, reguladora del Derecho a la Educación. Disponível em: https://www.boe.es/buscar/pdf/1985/BOE-A-1985-12978consolidado.pdf Acesso em: 10 abr. 2020.

ESPANHA. Real Decreto n. 1533, de 11 de julio de 1986, por el que se regulan las asociaciones de padres de alumnos. Disponível em:

https://www.boe.es/boe/dias/1986/07/29/pdfs/A26858-26859.pdf Acesso em: 10 abr. 2020.

ESPANHA. Orden de 29 de junio de 1994a, por la que se aprueban las instrucciones que regulan la organización y funcionamiento de las Escuelas de Educación Infantil y de los Colegios de Educación Primaria. Disponível em: https://www.boe.es/buscar/pdf/1994/BOEA-1994-15723-consolidado.pdf. Acesso em: 10 abr. 2020.

ESPANHA. Orden de 11 de octubre de 1994b, por la que se regula la actividad de voluntariado en los centros públicos que impartan enseñanzas de régimen general. Disponível em: https://www.boe.es/eli/es/o/1994/10/11/(3)/dof/spa/pdf Acesso em: 10 abr. 2020.

ESPANHA. Ley Orgánica n. 9, de 20 de noviembre de 1995, de la participación, la evaluación y el gobierno de los centros docentes. Disponível em:

https://www.boe.es/boe/dias/1995/11/21/pdfs/A33651-33665.pdf Acesso em: 10 abr. 2020.

ESPANHA. Las actividades extraescolares en los centros educativos. Madrid: Artegraf, 1996a.

ESPANHA. Real Decreto n. 82, de 26 de enero de 1996b, por el que se aprueba el Reglamento Orgánico de las Escuelas de Educación Infantil y de los Colegios de Educación Primaria. Disponível em: https://www.boe.es/buscar/pdf/1996/BOE-A-1996-3689consolidado.pdf Acesso em: 10 abr. 2020. 
ESPANHA. Ley Orgánica n. 8, de 9 de diciembre de 2013, para la mejora de la calidad educativa. Disponível em: https://www.boe.es/buscar/pdf/2013/BOE-A-2013-12886consolidado.pdf Acesso em: 10 abr. 2020.

ESPANHA. Estadísticas. Enseñanza no universitária. Centros y servicios educativos. Curso 2017-2018. 2019. Disponível em: http://www.educacionyfp.gob.es/servicios-al-ciudadanomecd/estadisticas/educacion/no-universitaria/centros/centros-servicios.html. Acesso em: 10 abr. 2020.

FERNÁNDEZ ENGUITA, Mariano. La jornada escolar. Barcelona: Ariel, 2001.

FERRER JULIÁ, Ferran. La educación comparada actual. Barcelona: Ariel, 2002.

FERRETTI, Celso João; VIANNA, Claudia Pereira; SOUZA, Denise Trento de. Escola pública em tempo integral. Cadernos de Pesquisa, São Paulo, n.76, p. 5-17, fev. 1991. Disponível em: http://publicacoes.fcc.org.br/ojs/index.php/cp/article/view/1049/1057 Acesso em: 10 abr. 2020.

GARCÍA GARRIDO, José Luis. Educación comparada: fundamentos y problemas. Madrid: Editorial Dykinson, 1982.

GARCÍA GARRIDO, José Luis (coord.). La sociedad educadora. Madrid: Fundación Independiente, 2000.

LA CIUDAD EDUCADORA. Ajuntament de Barcelona: Barcelona, 1990. [I Congrés Internacional de Ciutats Educadores].

LÁZARO HERRERO, Luján. La perspectiva social de la jornada escolar en la Unión Europea. Estudio comparado en Italia, Francia, Portugal y España. Tesis Doctoral. Universidad de Salamanca, Salamanca, 2007.

LÁZARO HERRERO, Luján. El modelo de jornada escolar en España: panacea educativa o reivindicación sectorial? Educação em Revista, Marília, v.18, Edição Especial, p. 07-22, 2017. Disponível em:

https://www2.marilia.unesp.br/index.php/educacaoemrevista/article/view/6772 Acesso em: 10 abr. 2020.

LIMA, Licínio C. A escola como organização educativa: uma abordagem sociológica. São Paulo: Cortez, 2011.

MIGNOT, Ana Chrystina Venancio. CIEP - Centro Integrado de Educação Pública: alternativa para a qualidade do ensino ou nova investida do populismo na educação? Em Aberto, n. 44, p. 45-63, 1989. Disponível em:

http://rbep.inep.gov.br/ojs3/index.php/emaberto/article/view/2080 Acesso em: 10 abr. 2020.

MOLL, Jaqueline. et al. Caminhos da Educação Integral no Brasil: direito a outros tempos e espaços educativos. Porto Alegre: Penso, 2012.

MOREIRA, Antonio Flavio; SILVA, Tomaz Tadeu da (orgs.). Currículo, cultura e sociedade. São Paulo: Cortez, 2008. 
PARENTE, Cláudia da Mota Darós. Construindo uma Tipologia das Políticas de Educação Integral em Tempo Integral. Roteiro, v. 41, n. 3, p. 563-586, 2016. Disponível em: https://portalperiodicos.unoesc.edu.br/roteiro/article/view/10601 Acesso em: 10 abr. 2020.

PARENTE, Cláudia da Mota Darós. Políticas de Educação Integral em Tempo Integral à Luz da Análise do Ciclo da Política Pública. Educação e Realidade, Porto Alegre, v. 43, n.2, p. 415-434, 2018. Disponível em: https://www.scielo.br/scielo.php?pid=S217562362018000200415\&script=sci_abstract\&tlng=pt Acesso em: 10 abr. 2020.

PARENTE, Cláudia da Mota Darós; LÁZARO HERRERO, Luján. Educação em tempo integral e mais tempo na escola: estratégias de Brasil e Espanha. InterMeio: revista do Programa de Pós-Graduação em Educação, Campo Grande, MS, v. 25, n. 50, p. 31-56, jul./dez. 2019. Disponível em: https://periodicos.ufms.br/index.php/intm/article/view/9416 Acesso em: 10 abr. 2020.

PARO, Vitor Henrique et al. Escola de tempo integral: desafio para o ensino público. São Paulo, Cortez, 1988.

PEREYRA, Miguel A. La jornada escolar y su reforma en España: un marco de comprensión. In: PEREYRA, M. A.; FARACO, J. C. G.; CORONEL, J. M. Infancia y escolarización en la modernidad tardía. Andalucia: Akal; Universidad de Andalucia, 2002. p. 71-104.

PEREYRA, Miguel A. A vueltas con la jornada y los tiempos escolares en el comienzo de una nueva época. Andalucía: Observatorio de la Infancia en Andalucía, 2005. Disponível em: https://www.observatoriodelainfancia.es/oia/esp/documentos_ficha.aspx?id=551. Acesso em: 01 mai. 2020.

PETITAT, André. Produção da escola, produção da sociedade: análise sócio-histórica de alguns momentos decisivos da evolução escolar no ocidente. Porto Alegre, Artes Médicas, 1994.

RIBETTO, Anelice; MAURÍCIO, Lúcia Velloso. Duas décadas de educação em tempo integral: dissertações, teses, artigos e capítulos de livros. Em Aberto, v. 22, n. 80, p. 137-160, 2009.

SACRISTÁN, José Gimeno. Saberes e incertezas sobre o currículo. Porto Alegre: Penso, 2013.

SOUZA, Donaldo Bello de; BATISTA, Neusa Chaves. Educação Comparada BrasilEspanha: Estado da Arte 1990-2014. Ensaio: Avaliação de Políticas Públicas e Educação, v. 26, n.100, p. 723-758, 2018.

TRILLA, Jaume. Introducción. In: LA CIUDAD EDUCADORA. Ajuntament de Barcelona: Barcelona, 1990. [I Congrés Internacional de Ciutats Educadores). p. 13-21.

TRILLA, Jaume. La educación fuera de la escuela: ámbitos no formales y educación social. Barcelona: Ariel, 1998. 
UNESCO - United Nations Educational, Scientific and Cultural Organization. Education for All 2000-2015: achievements and challenges; EFA global monitoring report, 2015 Paris: Unesco, 2015.

\section{$\underline{\text { SOBRE A AUTORA }}$}

\section{Cláudia da Mota Darós Parente}

Doutora em Educação pela Universidade Estadual de Campinas (Unicamp); Professora da Universidade Estadual Paulista (Unesp); Líder do Grupo de Pesquisa e Avaliação de Políticas Educacionais (Gape). E-mail: claudia.daros@unesp.br

(iD http://orcid.org/0000-0003-0250-8935

Recebido em: 05 de maio de 2020 